\title{
O Pisa como indicador de aprendizagem de Ciências
}

\author{
Pisa as indicator of science learning \\ El Pisa como un indicador del aprendizaje de las ciencias \\ Wanessa Cristiane Gonçalues Fialho' \\ Universidade Estadual de Goiás, Docente Assistente II \\ https://orcid.org/0000-0002-0896-1362 \\ Samuel Mendonça ${ }^{2}$ \\ Pontifícia Universidade Católica de Campinas, Professor Titular \\ https://orcid.org/0000-0002-2918-0952
}

Resumo: 0 Programa Internacional de Avaliação de Alunos (Pisa) é um programa de avaliação comparada da aprendizagem de alunos, criado por paises membros da Organização para a Cooperação e Desenvolvimento Econômico (OCDE). 0 objetivo deste artigo foi analisar os resultados do Brasil no conteúdo de Ciências, nos anos de 2006 e de 2015, no Pisa, procurando observar as mudanças ocorridas, em relação a aprendizagem de Ciências e em termos de políticas públicas para essas alterações. A metodologia utilizada foi a revisão de literatura, seguida de análise de documentos oficiais a partir de dados do Pisa e do Instituto Nacional de Estudos e Pesquisas Educacionais Anísio Teixeira (lnep). 0s resultados indicam que políticas públicas devem ser desenvolvidas para a melhoria do ensino de Ciências, que se encontra em segundo plano, em relação aos conteúdos de Português e Matemática.

Palavras-chave: Avaliação em Larga Escala. Pisa. Ensino de Ciências.

Abstract: The Programme for International Student Assessment (Pisa) is a comparative assessment of student learning program developed by member countries of the Organization for Economic $\mathrm{Co}^{-}$ operation and Development (OECD). The aim of this article was to analyze the results of Brazil in the content of Science, in the years 2006 and 2015, concerning Pisa results. The methodology used was based on a review literature, followed but an analysis of official documents using data from Pisa and Instituto Nacional de Estudos e Pesquisas Educacionais Anísio Teixeira (Inep) results, trying to observe

Doutoranda em Educação pela Pontificia Universidade Católica de Campinas; Mestra em Educação pela Universidade Federal de Uberlândia; wanessafialho76@gmail.com

2 Doutor em Filosofia da Educação pela Universidade Estadual de Campinas; Mestre em Filosofia pela Pontifícia Universidade Católica de Campinas; samuelm@puc-campinas.edu.br 
the changes that occurred in relation to the learning of sciences and their relations with the curriculum. The results indicate that public policies should be developed to improve Science education, which is in the background, in relation to Portuguese and Mathematics content.

Keywords: Evaluation in Large Scale. Pisa. Science teaching.

Resumen: El Programa Internacional de Avaliación de Alumnos (Pisa) es un programa de evaluación comparada del aprendizaje de los alumnos, creado por paises miembros de la Organización para la Cooperación y el Desarrollo Económico (OCDE). El objetivo de este artículo fue analizar los resultados de Brasil en el contenido de Ciencias, en los años de 2006 y de 2015, en el Pisa, buscando observar los cambios ocurridos, en relación al aprendizaje de ciencias y en términos de políticas públicas para esas alteraciones. La metodología utilizada fue la revisión de la literatura, seguida de análisis de documentos oficiales a partir de datos del Pisa y del Instituto Nacional de Estudos e Investigaciones Educativas Anísio Teixeira (lnep). Los resultados indican que las políticas públicas deben ser desarrolladas para mejorar la enseñanza de la Ciencias, que se encuentra en segundo plan, en relación a los contenidos de Portugués y Matemática.

Palabras-clave: Evaluación en larga escala. Pisa. Enseñanza de Ciencias.

Recebido em 17 de janeiro de 2019 Aceito em 05 de julho de 2019 Publicado em 18 de fevereiro de 2020

\section{INTRODUÇÃO}

Há uma cultura mundial em acreditar que as Avaliações em Larga Escala (ALE) representam indicador da qualidade da educação. A cada dia as ALEs vêm se constituindo critérios únicos para averiguar a qualidade do ensino dos estudantes, bem como ainda o que estudam, como e de que forma vêm aprendendo (FREITAS et al., 2012).

A avaliação educacional em larga escala faz parte das políticas públicas educacionais, como descrito, na Lei de Diretrizes e Bases da Educação (LDB), n. 9396/1996, atribuindo à União, o papel de "[...] assegurar processo nacional de avaliação do rendimento escolar no ensino fundamental, médio e superior, em colaboração com os sistemas de ensino, objetivando a definição de prioridades e a melhoria da qualidade do ensino" (BRASIL, 1996). № entanto, as avaliações externas não ficam restritas apenas ao âmbito Federal, elas também são realizadas pelos estados e municípios, com diferentes finalidades.

As ALEs têm o papel de diagnosticar a qualidade da aprendizagem, nos níveis Fundamental e Médio brasileiro (CASTRO, 2009). De acordo com Libâneo, Oliveira e Toschi (2012) 
essas avaliações, para o Ensino Básico, foram colocadas em prática desde 1994, podendo ser citadas, como exemplos o Sistema de Avaliação da Educação Básica - SAEB (1994), o Exame Nacional do Ensino Médio - ENEM (1998) e o Índice de Desenvolvimento da Educação Básica - IDEB (2007).

Apesar dessas avaliações já ocorrerem desde a década de 1990, mesmo tendo passado por diferentes governos e ocorridas várias mudanças em sua forma, elas continuam a ser aplicadas. Tanto as avaliações em larga escala, quanto as avaliações dos sistemas e a avaliação da aprendizagem se tornaram importantes, devido ao surgimento das avaliações tanto para o Ensino Básico, como descrito anteriormente, quanto “[...] para a educação superior, com o Programa de Avaliação Institucional das Universidades Brasileiras, (PAlUB), criado em 1993; e o Exame Nacional de Cursos (ENC), criado em 1995" (CALDERÓN; BORGES, 2013, p. 170).

Em se tratando das avaliações do Ensino Superior, desde a criação do Sistema de Avaliação da Educação do Ensino Superior (Sinaes), criado pela Lei n. 10.861 de 14 de abril de 2004, - Sinaes tornou-se importante fonte de regulação tanto dos gastos, quanto de financiamento ou de expansão das Universidades do país, promovendo consequências para a educação, como alterações curriculares, a existência do rankeamento das Instituições Superiores, mudanças para a prática docente, bem como na gerência dessas instituições. Nesse sentido, as avaliações tornaram-se pontos de controle dos gastos do Estado, "em geral, são avaliações externas, somativas, orientadas para o exame de resultados, realizadas ex post e seguem prioritariamente os paradigmas objetivistas e quantitativistas" (DIAS SOBRINHO, 2003, p. 60).

Dessa maneira "[...] as avaliações não levam em consideração as condições de partida de cada escola, a infraestrutura, os profissionais, suas formações, entre outros" (GARCIA et al., 2018, p. 196). Assim, analisar com mais profundidade como esse indicador da qualidade de ensino tem sido utilizado é importante para a investigação da realidade do ensino de Ciências.

No Brasil, observa-se que as políticas educacionais desenvolvidas, em especial para o Ensino Fundamental, ao longo dos últimos 25 anos, pelo Governo Federal, têm provocado uma tentativa de homogeneização das redes de ensino principalmente aos conteúdos curriculares e de avaliação. Porém, ao longo desses anos elas foram sendo relacionadas a outras políticas educacionais, aumentando o modelo pedagógico de desempenho escolar e exercendo mudanças na concepção de currículo, avaliação e pedagogia nas escolas, como um todo (MAINARDES, 2013). Em princípio pode-se dizer que as avaliações de sistemas de ensino são indicadores importantes da qualidade da educação no país, no entanto, trabalhos como o de Araújo e Tenório (2017) demonstram de forma aprofundada os usos e (des)usos dos resultados dessas avaliações na prática educativa, como por exemplo, essas avaliações podem ser utilizadas como critérios para priorização de área no Programa de Desenvolvimento Profissional de Professores (PDPP) e sugestões para os gestores nos relatórios brasileiros do Programa Internacional de Avaliação de Alunos (Pisa). E, como uso indevido dos resultados 
temos a divulgação inadequada na mídia, além dos resultados que não condizem com a situação real da educação brasileira.

Diante desse cenário, o interesse neste artigo é em especial sobre os resultados do Brasil no Pisa no conteúdo de Ciências, uma vez que esse conteúdo é contemplado nessa avaliação internacional e, no entanto, nas ALEs no Brasil, Ciências nem sempre é avaliado. Assim, procuraremos analisar os resultados do Pisa, comparando as provas dos anos de 2006 e 2015, para observar se ocorreram mudanças, nesse período, em relação aos resultados da aprendizagem das Ciências e, em termos de políticas públicas para essas alterações.

\section{METODOLOGIA}

A realização do presente estudo iniciou-se com uma revisão de literatura, no período de 2013 a 2018, em duas revistas científicas de alto impacto uma que tem como tema principal as avaliações educacionais, e outra que privilegia o ensino de Ciências, a saber: a revista Estudos em Avaliação Educacional e a revista Ensaio, Pesquisa em Ensino de Ciências.

Ao analisar os artigos na revista Estudos em Avaliação Educacional, no período indicado, foram encontrados cinco artigos: Garcia et al., (2018); Araújo e Tenório (2017); Vieira (2017); Medeiros, Jaloto e Santos (2017); Muri, Soares e Bonamino (2017).

Já na revista Ensaio também encontramos um artigo, de Pizarro e Júnior (2017), que fizeram um levantamento bibliográfico em revistas nacionais e internacionais sobre o conteúdo de Ciências no Pisa. As revistas foram consultadas na tentativa de buscar dados sobre pesquisas realizadas, levando-se em consideração, os resultados de Ciências, do Brasil, no Pisa.

Também foram consultados os anais da Associação Brasileira de Avaliação Educacional - Abave, nos anos de 2013 e 2015, por ser bianual. Essa busca resultou em um artigo encontrado de Muri e Ortigão (2013), no qual as autoras fazem uma análise dos resultados de Ciências, no Pisa, do ano de 2006, que será descrito nesse trabalho.

Além das revistas e dos anais fizeram parte de nossa pesquisa os dados obtidos do Pisa, tomando como fonte a Organização para a Cooperação e Desenvolvimento Econômico (OCDE), e o Instituto Nacional de Estudos e Pesquisas Educacionais Anísio Teixeira (INEP). Em especial foram consultados os documentos com as análises trazidas pelo INEP ao final do ano de aplicação do Pisa em estudo (BRASIL, 2015, 2016a). 
Documentos e sites do Governo Federal, livros e artigos de autores nessa área também fizeram parte desse estudo, como, por exemplo: Castro (2009); Correia, Arelado e Freitas (2015); Waiselfisz (2009), entre outros, para embasar o referencial teórico deste artigo.

\section{CONTEXTUALIZANDO O PISA}

0 Pisa diz respeito a um programa de avaliação comparada da aprendizagem de alunos, criado por países membros da Organização para a Cooperação e Desenvolvimento Econômico (OCDE), em 1997. Essa avaliação é realizada com alunos de idade entre 15 anos e 3 meses 16 anos e 2 meses completos, no início do ano de aplicação da prova e que estejam cursando, no mínimo o $7^{\circ}$ ano do Ensino Fundamental e sua finalidade é avaliar habilidades e competências dos estudantes para que esses possam ser inseridos na sociedade (BONAMINO; COSCARELLI; FRANCO, 2002).

A prova pisa é realizada de três em três anos, para aferir os conhecimentos e habilidades dos estudantes nos conhecimentos de Leitura, Matemática e Ciências, nos países membros da OCDE, que representam 35 países. É importante frisar que o número de países que aderem a essa prova, a cada ciclo aumenta, sendo que, em 2015, o número de países participantes alcançou o número 70. Desses, 35 são países membros da OCDE e os outros 35são países/economias parceiras (CARVALH0, 2016).

Apesar da prova Pisa ser realizada internacionalmente desde 1997, a participação brasileira vem ocorrendo desde o ano 2000. A cada aplicação da prova, uma das três áreas é privilegiada, com questões em maior quantidade, geralmente dois terços da prova, em peso, para averiguar os conhecimentos dos alunos, especialmente na área escolhida para a prova. Assim, as provas foram elaboradas visando o destaque dos Componentes Curriculares, de acordo com o Quadro 1, abaixo.

Quadro 1 - Aplicação do Pisa, no Brasil

\begin{tabular}{|c|c|c|c|c|c|c|}
\hline \multicolumn{1}{|c|}{ Pisa } & 2000 & 2003 & 2006 & 2009 & 2012 & 2015 \\
\hline Área em destaque & Leitura & Matemática & Ciências & Leitura & Matemática & Ciências \\
\hline
\end{tabular}

Fonte: Brasil (2016a)

0 Quadro 1, apresentado, mostra que a prova levou em consideração os conhecimentos de ciências, como principal referência para a aprendizagem, nos anos de 2006 e 2015. Em relação à comparação realizada entre as duas avaliações, no ano de 2006 
e 2015, isso só é possível, graça a Teoria de Resposta do Item - TRI. Para as avaliações que utilizam a TRI, são levados em consideração que: "[...] cada indivíduo possui uma habilidade latente e não observável, que se convenciona chamar de proficiência, cujo valor determina a probabilidade de acerto de uma pergunta, ou item, que mede essa mesma habilidade". (SOARES e NASCIMENTO, 2012, p. 73).

No caso da prova Pisa, a nota não é baseada apenas no número de acertos ou de erros, uma vez que as questões levam em consideração as habilidades cognitivas não observáveis, ao serem construídas em relação à vivência dos fatos reais, dos estudantes. Dessa forma, eles devem refletir sobre a realidade para responderem a prova.

Em relação às habilidades cognitivas, essas estão relacionadas ao letramento científico, que auxiliam o aluno, no cotidiano de sua vida, permitindo a ele "I...] fazer uma leitura crítica de mundo em que vive e como ele interage com este mundo, além de enxergar e analisar criticamente, como a sociedade em que ele vive interage, interpreta e transforma o ambiente que o cerca" (TEIXEIRA, 2007, p. 23).

Em outro trabalho, o letramento científico é definido como aquele proveniente do ensino de Ciências que "[...] almeja a formação cidadã dos estudantes para o domínio e uso dos conhecimentos científicos e seus desdobramentos nas mais diferentes esferas de sua vida" (SASSERON E CARVALHO, 2011, p. 60).

Assim, essas habilidades cognitivas são quantificadas no Pisa, devido às questões formuladas, que possuem um conteúdo relacionado aos fatos do cotidiano, em outras palavras, no Pisa 2015, o conceito de letramento científico se refere ao conhecimento de Ciências e de Tecnologia, baseada nas Ciências.

0 letramento científico é definido e caracterizado de diferentes formas, na prova Pisa. Em 2006, primeiro ano de avaliação, tendo como foco, o ensino de Ciências, o letramento científico foi desmembrado em dois componentes: "conhecimento de ciências" e "conhecimento sobre Ciências" (ORGANIZAÇÃO PARA A COOPERAÇÃO E DESENVOLVIMENTO ECONÔMICO, 2007), tendo como interesse o conhecimento da relação existente entre Ciência e Tecnologia. Já em 2015, como descrito no Quadro 2, o conceito de "conhecimento sobre Ciências" passou a ser subdividido em "conhecimento procedimental" e "conhecimento epistemológico". Assim, no Pisa 2015, letramento científico é definido por três competências: explicar fenômenos cientificamente, avaliar e planejar experimentos científicos e interpretar dados e evidências cientificamente. 
Quadro 2 - Categorias avaliadas em Ciências no Pisa 2015

\begin{tabular}{|c|c|c|c|c|c|}
\hline \multicolumn{3}{|c|}{ Dimensões do Letramento Cient́fico } & \multicolumn{3}{c|}{ Demais Categorias } \\
\hline Competências Científicas & $\begin{array}{c}\text { Tipos de Co- } \\
\text { nhecimentos }\end{array}$ & $\begin{array}{c}\text { Sistemas de } \\
\text { Conteúdo }\end{array}$ & $\begin{array}{c}\text { Tipos de Res- } \\
\text { postas }\end{array}$ & $\begin{array}{c}\text { Demanda } \\
\text { Cognitiva }\end{array}$ & Contextos \\
\hline $\begin{array}{c}\text { Explicar fenômenos } \\
\text { cientificamente }\end{array}$ & Conteúdo & $\begin{array}{c}\text { Sistemas } \\
\text { físicos }\end{array}$ & $\begin{array}{c}\text { Múltipla escolha } \\
\text { simples }\end{array}$ & Baixa & Pessoal \\
\hline $\begin{array}{c}\text { Avaliar e planejar experi- } \\
\text { mentos científicos }\end{array}$ & Procedimental & Sistemas vivos & $\begin{array}{c}\text { Múltipla escolha } \\
\text { complexa }\end{array}$ & Média & $\begin{array}{c}\text { Local } \\
\text { nacional }\end{array}$ \\
\hline $\begin{array}{c}\text { Interpretar dados e evi- } \\
\text { dências cientificamente }\end{array}$ & Epistemológico & $\begin{array}{c}\text { Sistema Terra } \\
\text { e espaço }\end{array}$ & $\begin{array}{c}\text { Resposta cons- } \\
\text { truída }\end{array}$ & Alta & Global \\
\hline
\end{tabular}

Fonte: Brasil (2015, p. 8)

Além dessas alterações conceituais, outros ajustes foram realizados, como, por exemplo, os conhecimentos atitudinais avaliados nos estudantes participantes da prova, em 2006, foram incluídos à matriz, quantificados nos questionários e no teste cognitivo aplicado. Já em 2015 essa medida foi realizada levando-se em consideração apenas o questionário respondido pelos participantes. Outra mudança, em relação à nomenclatura no Pisa 2015 foi em relação aos contextos, denominados de "pessoal, social e global", nas provas de 2006 e 2012, passaram a ser "pessoal, local/nacional e global" (BRASIL, 2016b).

A prova ainda levava em consideração, quanto ao tipo de questões, por grau de dificuldade, em fáceis, de média complexidade e alta demanda cognitiva. Outro fator importante, na análise da prova é a presença de questões abertas e questões de múltipla escolha.

\section{PISA NAS REUISTAS E ANAIS INUESTIGADOS}

A busca por artigos nas duas revistas aqui investigadas levou ao total de sete artigos encontrados que relacionavam os resultados do Pisa do Brasil com o conteúdo de Ciências, entre o período de 2013 a 2018.

Na revista Estudos em Avaliação Educacional foram investigados cinco trabalhos, entre eles o de Garcia et al., (2018) que fizeram uma pesquisa comparada entre Austrália, Brasil e Canadá apontando as principais consequências das ALEs para o ensino de Ciências. Nesse estudo os autores mostram um panorama geral dessas avaliações nos três países indicados. Eles afirmam que, no Brasil, a partir de 2001, as ALEs são baseadas exclusivamente nos conteúdos de Português e Matemática, enquanto que no cenário internacional o Brasil tem participado do Programa Internacional de Avaliação de Alunos - Pisa, que avalia a aprendizagem de estudantes nos conteúdos de Português, Matemática e de Ciências. Os 
resultados desse trabalho indicam que políticas de incentivo estão sendo criadas, assim como diversos projetos para a melhoria do ensino de Português e Matemática, enquanto que o conteúdo de Ciências vem sendo depreciado pela direção das escolas e do próprio sistema escolar, que privilegiam ações e metas a serem alcançadas apenas nos conteúdos de Português e Matemática, em decorrência da ênfase nesses conteúdos nas ALEs.

0 trabalho de Araújo e Tenório (2017) foi realizado a partir de uma revisão de literatura no período de 2000 a 2015 e entrevistas semiestruturadas com gestores de escolas básicas e responsáveis pelo Pisa no Brasil, com o objetivo de mapear os usos e não usos dos resultados do Pisa em políticas públicas de melhorias para o ensino. Como resultados desse trabalho foram encontrados poucos grupos de pesquisadores que relacionam os resultados do Pisa e políticas públicas voltadas para ações que promovessem de fato melhorias do ensino. De acordo com os autores os resultados do Pisa no Brasil têm sido utilizados muito mais para confirmar que o Brasil vai mal na educação do que incentivar ações de melhorias reais educacionais.

Vieira (2017) utilizou-se da metodologia de análise teórica-comparativa entre as normas do Pisa 2015 e as normas que regem o ensino de Ciências brasileiro do último século. Como resultados foram encontrados muito mais dissonâncias do que sintonias entre os objetivos do Pisa e a aprendizagem dos conteúdos científicos brasileiros. Dessa forma, a autora esclarece que é preciso uma reflexão sobre a utilidade do Pisa para avaliar a educação brasileira, visto que os objetivos educacionais dos dois não são os mesmos, o que gera conflitos e resultados ruins tanto para estudantes, quanto para professores, que são sempre responsabilizados pelo baixo desempenho nessa prova.

Medeiros, Jaloto e Santos (2017) procuraram abordar os aspectos pedagógicos da prova Pisa de 2015 e do Terceiro Estudo Regional Comparativo e Explicativo (TERCE), levando em consideração o conteúdo de Ciências dessas provas internacionais. Para essa finalidade apresentaram e discutiram os pontos conceituais e procedimentais dessas provas mostrando alguns resultados de desempenho dos estudantes brasileiros. Ao final do estudo os autores sinalizaram para a necessidade de reflexão sobre os resultados dessas provas para a construção de políticas efetivas para o ensino de Ciências visando, em especial, as recentes alterações curriculares, como previsto na nova Base Nacional Comum Curricular (BNCC) e nas avaliações do Plano Nacional de Educação (PNE).

Para Muri, Soares e Bonamino (2017) um estudo comparativo entre Brasil e Japão, nos resultados do Pisa, edição 2006, representou uma tentativa de buscar explicações para as diferenças entre os resultados, com relação ao letramento em Ciências. Os resultados apontaram que existiram itens que eram mais fáceis para os estudantes brasileiros enquanto outros eram mais fáceis para os japoneses, como: os itens "meio ambiente", "saúde" e "recursos naturais" representavam áreas mais fáceis para os estudantes brasileiros enquanto que os 
itens relacionados a "limites da ciência e tecnologia" e "riscos", eram mais fáceis para os estudantes japoneses. Apesar dessas diferenças encontradas, de acordo com os autores, testes que levam em consideração TRI em geral não apresentam muitas diferenças nos itens utilizados para a formulação das questões, apesar de haver diferenças devido a presença de países tão diferentes que participam dessa avaliação, como foi o caso de Brasil e Japão aqui investigados. Os autores terminam o estudo afirmando que o Pisa aparenta ser realizado com qualidade e uma boa forma de comparar os resultados brasileiros e japoneses.

Na revista Ensaio foi encontrado um estudo de Pizarro e Júnior (2017), que fizeram um levantamento bibliográfico em periódicos nacionais e internacionais que levam em consideração a área do ensino de Ciências. Para essa finalidade procuraram trabalhos com o tema alfabetização científica e as relações com as avaliações em larga escala. Entre os resultados foi encontrado uma preocupação com as repercussões em relação aos resultados do Pisa e, por isso os autores encerram o trabalho apontando a importância de novas pesquisas que relacionam os resultados do Pisa a ações para melhorias do ensino de ciências.

Por fim, nos anais da Associação Brasileira de Avaliação Educacional - Abave foi encontrado o estudo de Muri e Ortigão (2013) no qual analisaram os resultados do Pisa, no conteúdo de Ciências, na edição de 2006. Esse estudo teve como objetivo investigar a formação científica dos estudantes a partir do Pisa, que prioriza as competências científicas e quais são as características dos estudantes relacionadas aos resultados obtidos. Como resultados apontados pelas autoras, o Brasil apresentou um baixo desempenho em relação as competências científicas, e a justificativa encontrada por elas está principalmente nas diferenças de ensino oferecidos entre as escolas públicas e particulares e nas condições socioeconômicas desses estudantes que participam. Assim, afirmam as autoras que as maiores médias dos estudantes brasileiros que estão concentradas nos níveis 2 e 3 são de estudantes provenientes de escolas particulares e que possuem um nível socioeconômico alto. Em decorrência disso, elas encerram seu estudo afirmando que é preciso colocar em prática ações e políticas educacionais para melhorias do ensino de Ciências, uma vez que o objetivo do Pisa é apresentar um indicador de qualidade do ensino e, dessa forma, cabe aos gestores educacionais, a partir desse indicador, promover ações para as reais mudanças educacionais.

A partir dos trabalhos elencados e investigados foi possível inferir que a maioria deles aponta que o Pisa cumpre o seu papel, de apresentar um indicador da aprendizagem escolar dos estudantes. Uma vez que os países participantes são muito diferentes culturalmente falando e, em termos de tipo de ensino ofertado, é evidente que ocorrem algumas diferenças nos resultados apresentados que devem ter cautela, ao serem comparados. Entretanto, a maioria dos trabalhos apresentam dados em comuns, ao afirmarem que é preciso utilizar 
na prática os resultados brasileiros para reais ações e políticas públicas para melhorias do ensino de Ciências, por ser esse um importante conhecimento para a inserção do indivíduo no mundo tecnológico ao qual vivenciamos.

\section{RESULTADOS DO PISA DE 2006 E 2015}

Em relação ao ano de 2006, primeiro ano que o conteúdo de Ciências foi privilegiado com o maior número de questões, Muri e Ortigão (2013) analisaram a média obtida brasileira, comparando-a com os outros países participantes da prova. A partir dos dados obtidos do conteúdo de ciências, nas diferentes edições em que ele foi privilegiado temos o Gráfico 1.

Gráfico 1 - Médias de alguns paises no Pisa

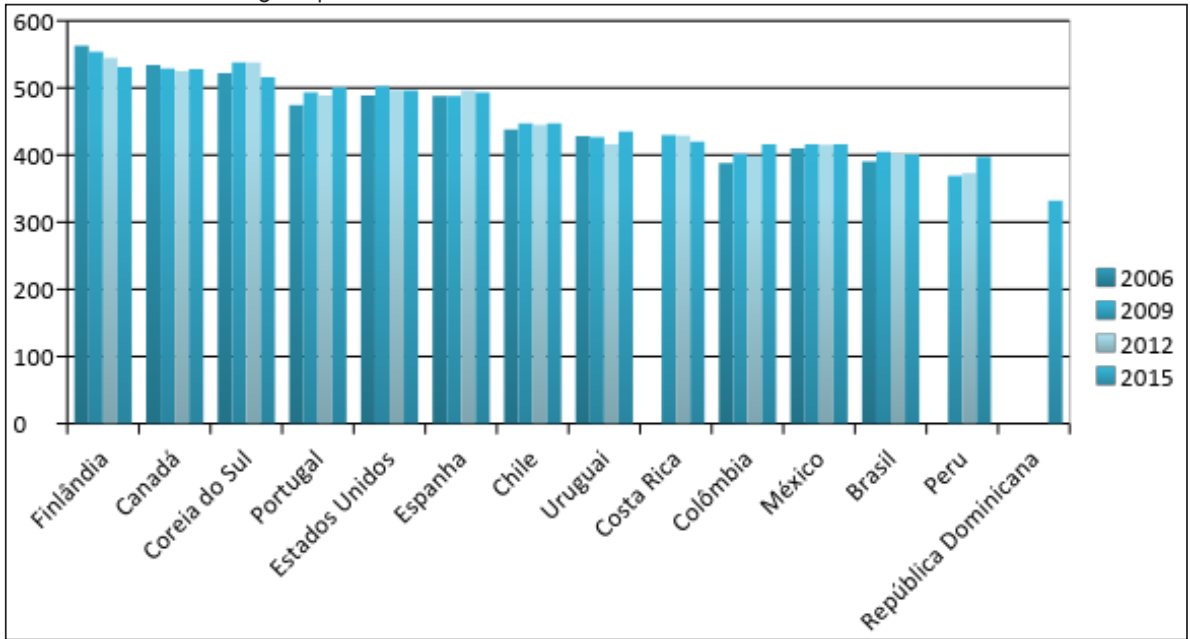

Fonte: elaboração com base em Brasil (2016a)

As análises do Gráfico 1 mostram que alguns países não participaram da prova em todos os anos e, por isso, não apresentam todas as colunas. Como exemplo, temos a Costa Rica e Peru, que só começaram a participar no ano de 2009 e a República Dominicana, que só veio a participar na última edição, em 2015.

Ao se observar o Gráfico 1 constata-se que o Brasil ocupou a posição de $52^{\circ}$ lugar, entre os 57 países participantes, permanecendo na frente apenas de Colômbia (53 lugar), quando comparamos aos vizinhos sul-americanos, que possuem condições socioeconômicas semelhantes à brasileira. 
Por outro lado, as análises dos dados obtidos pelo Brasil, no Pisa, ao longo dos anos citados no gráfico anterior, mostram uma pequena melhora na média, após o ano de 2006, para o conteúdo de Ciências, como demonstrado na Tabela 1.

Tabela 1 - Médias do Brasil em Ciências

\begin{tabular}{ccccc}
\hline Pisa & 2006 & 2009 & 2012 & 2015 \\
\hline Médias & 390 & 405 & 402 & 401 \\
\hline
\end{tabular}

Fonte: Brasil (2016a)

Apesar das diferenças na pontuação na Tabela 1, as médias confirmam que desde 2006 os valores têm-se mantido constantes, levando-se em consideração os erros padrões da média, na edição avaliada.

Em contrapartida, uma das análises realizadas no Pisa 2015, diz respeito ao índice de estudantes brasileiros com idade de 15 anos que participaram da prova no referido ano. Ao considerarmos o quantitativo de alunos matriculados nas séries adequadas para a realização da prova, ou seja, a partir do $7^{\circ}$, ocorreu um aumento, em comparação com as provas anteriores (SOARES; NASCIMENTO, 2012), entretanto a permanência dos jovens nessa faixa etária, nas escolas, não é alcançada, em sua plenitude. Esse dado é observado a partir da última prova Pisa, realizada em 2015, quando o índice de estudantes encontrados foi "[...] em torno de $17 \%$ deles estavam fora da escola ou matriculados no $6^{\circ}$ ano ou em séries inferiores." (BRASIL, 2016a, p. 28). Esses dados demonstram que o índice de cobertura na prova, de estudantes brasileiros, que participaram dela, configurou-se em $71 \%$, devido a outros fatores ainda, como de exclusões e distorções, nos gráficos realizados.

Em outro estudo, Araújo e Tenório (2017) alertam para o baixo desempenho brasileiro no Pisa, alegando também essa relação idade/ano escolar, inferior a outros países, onde os estudantes já completaram um ciclo de estudos. Ainda há, no caso brasileiro, a possibilidade de estudantes fora da idade escolar cursarem os programas de educação para jovens e adultos (EJA), o que pode refletir também no baixo desempenho desses participantes da prova.

Esses dados comprovam o índice de alunos matriculados no Ensino Médio, que é inferior a $50 \%$, e a qualidade do ensino também pode ser analisada a partir dos indicadores do Sistema de Avaliação da Educação Básica - Saeb. Esse representa um dos indicadores de desempenho cognitivo dos estudantes matriculados no Ensino Básico brasileiro. Essa avaliação é aplicada nos alunos do $5^{\circ}$ e $9^{\circ}$ anos do Ensino Fundamental e no $3^{\circ}$ ano do Ensino Médio (SOARES; NASCIMENTO, 2012). 
As análises desses índices demonstram claramente o gargalo na educação do Ensino Básico brasileiro, apresentando um baixo índice de estudantes matriculados, em especial no Ensino Médio, sugerindo, para o futuro, problemas como a baixa demanda de estudantes no Ensino Básico (BARRET0, 2012).

Esses dados confirmam que o Brasil vem perdendo espaço em relação à Ciência, Tecnologia e Sociedade - CTS, na comparação com outros países, o que é ruim para os avanços tecnológicos, científicos e de inserção na sociedade dos estudantes brasileiros.

Por outro lado, esse baixo índice de estudantes matriculados no Ensino Médio é consequência direta da porcentagem daqueles estudantes que trabalham, em torno de 15 - $16 \%$. Uma forma de minimizar essas consequências para essa baixa demanda, em todos os níveis educacionais no Brasil é por meio de políticas públicas de educação e incentivos financeiros específicos para a faixa de quinze a dezessete anos (BRASIL, 2016a).

Em relação aos resultados do Pisa 2015, podemos fazer uma análise a partir do Gráfico 2, que apresenta as notas médias dos estudantes brasileiros, comparando-os com outros países que participaram dessa avaliação.

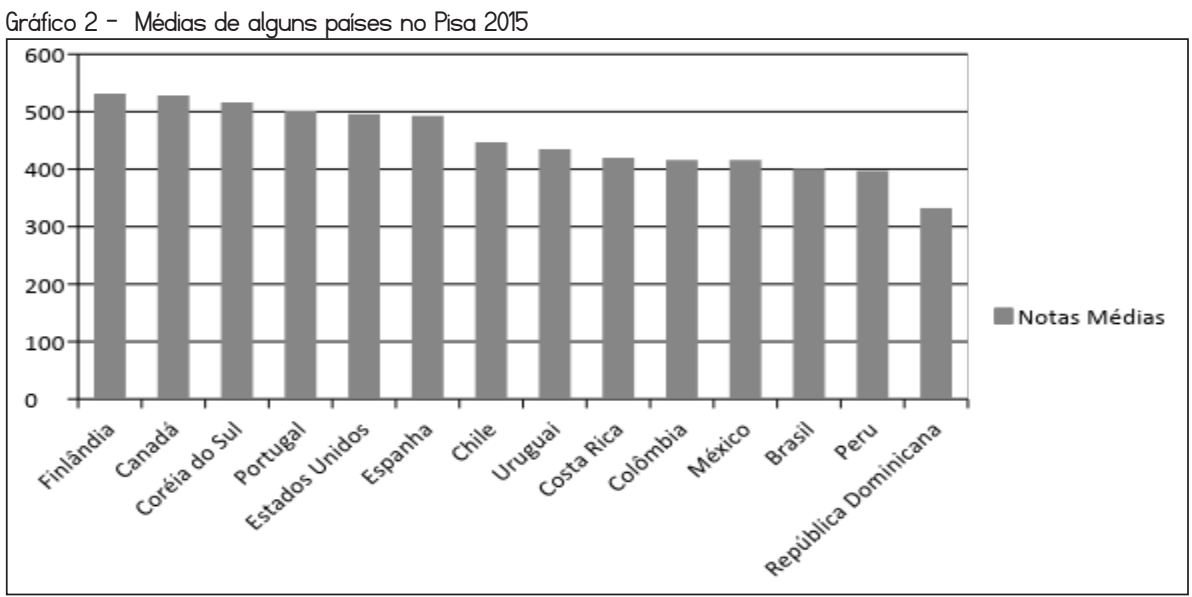

Fonte: elaboração com base em Brasil (2016a)

É importante afirmar que a nota do Brasil foi de 401 pontos, enquanto o Peru obteve uma nota média de 397 pontos e a República Dominicana 332, por esse motivo o Brasil ficou na frente desses países citados. Por outro lado, essa nota brasileira foi inferior a conquistada em 2012, colocando o Brasil, em 2015, na posição de $63^{\circ}$ colocação, na área de Ciências (GARCIA et al., 2018). 
Outra análise realizada, nos resultados de Ciências, leva em consideração os níveis de proficiência do estudante. Nesse caso, são observadas as habilidades e competências que a prova exige. Em relação a essas análises, Mainardes (2013), afirma que existem dois modelos pedagógicos nas escolas, o modelo de desempenho e o de competências.

No modelo pedagógico de desempenho, ganha ênfase o resultado dos estudantes nas provas. Dessa forma, ocorre uma diferenciação entre estudantes, favorecendo aqueles que têm um desempenho escolar melhor e prejudicando aqueles que precisam de mais tempo para aprender um conteúdo. Já o modelo pedagógico de competências se preocupa menos em produzir essas diferenças entre os estudantes. Entretanto, nesse modelo os custos são maiores, os professores têm maior autonomia para as mudanças curriculares e, a avaliação leva em consideração a aprendizagem do estudante de forma contínua. Mas, para que esse modelo possa ser efetivado, as escolas precisam mudar sua estrutura, apresentando turmas menores, acompanhamento pedagógico e da aprendizagem dos estudantes. Esse é o modelo adequado para a educação dos jovens e aprendizagem dos conhecimentos de forma ampla (MAINARDES, 2013).

Mas, as redes de ensino brasileiras utilizam o modelo pedagógico de desempenho, visando o resultado dos estudantes nas provas e, no Pisa são cobrados, nas questões, conhecimentos de acordo com o modelo de competências. 0 quadro com a descrição dos sete níveis de proficiência define, em cada nível, os conhecimentos e habilidades necessários para a realização da questão e foram baseados nas demandas cognitivas exigidas. 0 Quadro 3 apresenta cada nível e o conjunto de competências cobradas.

Quadro 3 - Níveis de proficiência em Ciências no Pisa 2015

\begin{tabular}{|c|l|}
\hline Nivel & \multicolumn{1}{c|}{ Características } \\
\hline 6 & $\begin{array}{l}\text { Os estudantes podem recorrer a uma série de ideias e conceitos científicos interligados de Física, } \\
\text { Ciências da Vida, Terra e Espaço e usar conhecimentos de conteúdo, procedimental e epistemológico } \\
\text { para formular hipóteses explicativas para novos fenômenos científicos, eventos e processos ou para } \\
\text { fazer suposições. Ao interpretar dados e evidências, conseguem fazer a discriminação entre infor- } \\
\text { mação relevante e irrelevante e podem recorrer a conhecimento externo ao currículo escolar. Podem } \\
\text { distinguir argumentos baseados em teorias e evidência científica dos baseados em outros fatores. Os } \\
\text { estudantes do nível } 6 \text { podem avaliar projetos concorrentes de experimentos complexos, estudos de } \\
\text { campo ou simulações e justificar suas escolhas. }\end{array}$ \\
\hline 5 & $\begin{array}{l}\text { Os estudantes podem usar ideias ou conceitos científicos abstratos para explicar fenômenos } \\
\text { incomuns e mais complexos, eventos e processos que envolvam relações causais múltiplas. Eles } \\
\text { conseguem aplicar conhecimento epistemológico mais avançado para avaliar projetos experimentais } \\
\text { alternativos, justificar suas escolhas e usar conhecimento teórico para interpretar informações e } \\
\text { fazer suposições. Os estudantes do nível } 5 \text { podem avaliar formas de explorar determinado problema } \\
\text { cientificamente e identificar limitações na interpretação de dados, incluindo fontes e os efeitos de } \\
\text { incerteza dos dados científicos. }\end{array}$ \\
\hline
\end{tabular}




\begin{tabular}{|c|c|}
\hline Nivel & Características \\
\hline 4 & $\begin{array}{l}\text { Os estudantes conseguem usar conhecimento de conteúdo mais complexo e mais abstrato, propor- } \\
\text { cionado ou recordado, para construir explicações de eventos e processos mais complexos ou pouco } \\
\text { conhecidos. Podem conduzir experimentos que envolvam duas ou mais variáveis independentes } \\
\text { em contextos restritos. Conseguem justificar um projeto experimental recorrendo a elementos de } \\
\text { conhecimento procedimental e epistemológico. Os estudantes do nível } 4 \text { podem interpretar dados } \\
\text { provenientes de um conjunto moderadamente complexo ou de contexto pouco conhecido, chegar a } \\
\text { conclusões adequadas que vão além dos dados e justificar suas escolhas. }\end{array}$ \\
\hline 3 & $\begin{array}{l}\text { Os estudantes podem recorrer a conhecimento de conteúdo de moderada complexidade para iden- } \\
\text { tificar ou formular explicações de fenômenos conhecidos. Em situações mais complexas ou menos } \\
\text { conhecidas, podem formular explicações desde que com apoio ou dicas. Podem recorrer a elementos } \\
\text { de conhecimento procedimental e epistemológico para realizar um experimento simples em contexto } \\
\text { restrito. Os estudantes do nível } 3 \text { conseguem fazer distinção entre questões científicas e não científi- } \\
\text { cas e identificar a evidência que apoia uma afirmação científica. }\end{array}$ \\
\hline 2 & $\begin{array}{l}\text { Os estudantes conseguem recorrer a conhecimento cotidiano e a conhecimento procedimental básico } \\
\text { para identificar uma explicação científica adequada, interpretar dados e identificar a questão aborda- } \\
\text { da em um projeto experimental simples. Conseguem usar conhecimento científico básico ou cotidiano } \\
\text { para identificar uma conclusão válida em um conjunto simples de dados. Os estudantes do nível } 2 \\
\text { demonstram ter conhecimento epistemológico básico ao conseguir identificar questões que podem } \\
\text { ser investigadas cientificamente. }\end{array}$ \\
\hline $1 \mathrm{~A}$ & $\begin{array}{l}\text { Os estudantes conseguem usar conhecimento de conteúdo e procedimental básico ou cotidiano } \\
\text { para reconhecer ou identificar explicações de fenômenos científicos simples. Com apoio, conseguem } \\
\text { realizar investigações científicas estruturadas com no máximo duas variáveis. Conseguem identificar } \\
\text { relações causais ou correlações simples e interpretar dados em gráficos e em imagens que exijam } \\
\text { baixo nível de demanda cognitiva. Os estudantes do nivel 1A podem selecionar a melhor explicação } \\
\text { científica para determinado dado em contextos global, local e pessoal. }\end{array}$ \\
\hline १B & $\begin{array}{l}\text { Os estudantes podem usar conhecimento científico básico ou cotidiano para reconhecer aspectos } \\
\text { de fenômenos simples e conhecidos. Conseguem identificar padrões simples em fontes de dados, } \\
\text { reconhecerem termos científicos básicos e seguir instruções explícitas para executar um procedi- } \\
\text { mento científico. }\end{array}$ \\
\hline$<\mathrm{B}$ & A OCDE não \\
\hline
\end{tabular}

Fonte: elaboração com base em Brasil (2016a).

A partir dos dados do Quadro 3 também é possível construir a Tabela 2 comparativa, observando o percentual de estudantes em cada nível de proficiência, para o conteúdo de Ciências, nos anos de 2006 e 2015. 
Tabela 2 - Percentual de alunos brasileiros, por proficiência, no Pisa, de 2006 e 2015

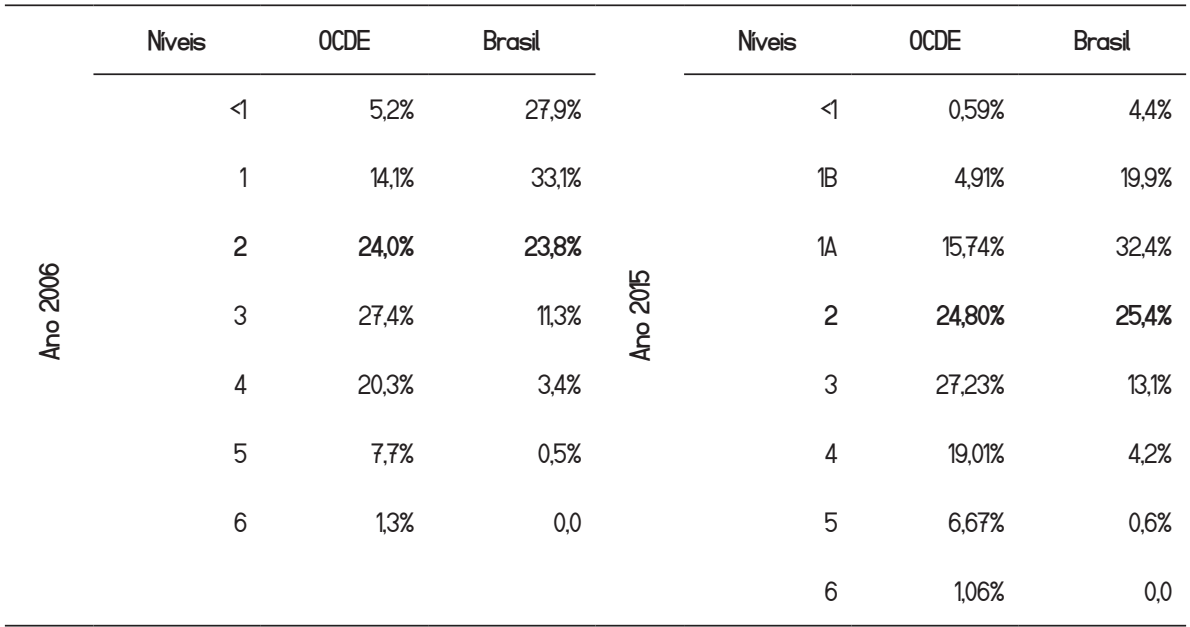

Fonte: elaboração com base em Brasil (2016a)

Notas:

1. 0 nivel 1 A corresponde ao nível 1 no Pisa 2006.

2. 0 nivel $1 \mathrm{~B}$ corresponde ao nivel 4 no Pisa 2006.

3. 0 nível 2 está em negrito para melhor visualização dos dados.

Os niveis de proficiência em Ciências foram criados para comparar as notas dos estudantes em um determinado ponto da escala, sendo que, quanto maior o valor na escala, maior a proficiência. Para a realização dessa escala, levaram-se em consideração as notas médias dos paises da $O C D E$, quinhentos pontos, e o desvio padrão de cem pontos, de acordo com o Pisa de 2006, onde essa escala foi determinada pela primeira vez (BRASIL, 2016a).

A escala criada para a análise das notas é representada por seis níveis de proficiência, criada em 2006. Já em 2015, essa escala possuía sete niveis, um a mais. 0 nivel criado foi o $1 \mathrm{~B}$, que indica as atividades mais difíceis de realização na prova. E, para informar os alunos que obtiveram nota inferior ao nivel $1 \mathrm{~B}$, foi criado, em 2015, o nivel abaixo de $1 \mathrm{~B}$. Para a OCDE, os paises devem atingir pelo menos o nível dois de proficiência, indicando dessa forma melhorias no aprendizado de Ciências, que podem ter consequências positivas para o desenvolvimento cient́fíico, tecnológico e da pessoa, como forma de inserção social e para o trabalho.

Fazendo uma análise dos dados percentuais na Tabela 2, é possivel notar uma melhora do Brasil, no nivel 2, considerado o nivel importante para o desenvolvimento das características e habilidades necessárias para o desenvolvimento do educando e sua inserção na sociedade e no mundo do trabalho.

Ainda com relação aos niveis de proficiência, no quadro anterior mencionado, Muri e Ortigão (2013) e Waiselfisz (2009) também fizeram essa análise, no ano de 2006, 
confirmando que o Brasil possui os maiores percentuais de alunos nos níveis mais baixos da escala $(27,9 \%$ no Nivel $<1 ; 33,1 \%$ no Nivel 1 e $23,8 \%$ no Nivel 2 ), o que significa um total de $84,8 \%$, aproximadamente, de estudantes nestes níveis. Já no ano de 2015 , o total desses níveis cai para 82,1\% dos estudantes, demonstrando uma pequena melhora na proficiência em ciências.

Ao comparar o Quadros 3 e a Tabela 2 é possivel verificar que uma porcentagem pequena de participantes conseguiu atingir os dois níveis mais altos das escalas, níveis 5 e 6 , o que não soma nem $1 \%$ do total. Esses níveis da escala são caracterizados por competências relacionadas aos processos de investigação científica, conhecimentos abstratos e de formulações e resoluções de problemas que extrapolam o currículo escolar.

Também é possível observar, na comparação do Quadro 3 e Tabela 2 que mais de $50 \%$ dos estudantes encontram-se na faixa abaixo do nível 2 , ou seja, mais da metade dos participantes da prova, em 2015, não são capazes de resolver questões simples. Nesse sentido, "[...] os estudantes conseguem apenas usar o conhecimento de conteúdo e procedimental básico ou cotidiano para reconhecer ou identificar explicações de fenômenos científicos simples" (BRASIL, 2016a, p. १1) conforme descrito no nível 1A, do Quadro 3.

Ainda, ao se analisarem os resultados anteriores, os estudantes apresentaram como "pontos fracos", ao responderem a prova em 2015 a "[...] competência de interpretar dados e evidências cientificamente, de conhecimento procedimental, de resposta do tipo aberta e múltipla escolha complexa" (BRASIL, 2016a, p. 11). Já as questões que tiveram maior índice de acerto, foram aquelas que levaram em consideração "[...] os itens da competência explicar fenômenos cientificamente, de conhecimento de conteúdo, de resposta do tipo múltipla escolha simples" (BRASIL, 2016a, p. 11).

Em relação a esses conhecimentos Maia e Justi (2008) desenvolveram um estudo comparativo com ALE em relação às questões e conhecimentos científicos cobrados. Nesse trabalho, as autoras afirmaram que essas provas em larga escala geralmente trazem os objetivos para o ensino de Ciências de forma bastante genérica ou superficial. Para elas, essas provas deveriam ser desconsideradas do processo de aprendizagem escolar, uma vez que ocorrem de forma descontínua, não tem relação com o contexto escolar e ocorrem segundo uma metodologia diferente da adotada pelo professor, em cada sala de aula.

Em relação à nota média dos estudantes brasileiros, pode-se fazer uma análise, por tipo de escola, onde esses jovens se encontram matriculados em escolas públicas: estaduais, municipais ou federais e as escolas particulares. Ao lançarmos esses dados no Gráfico 3, podemos observar as diferenças existentes nas diferentes unidades de ensino, do ponto de vista da natureza de sua administração. 
Gráfico 3 - Notas dos estudantes brasileiros, em Ciências, no Pisa 2015, em diferentes tipos de escolas

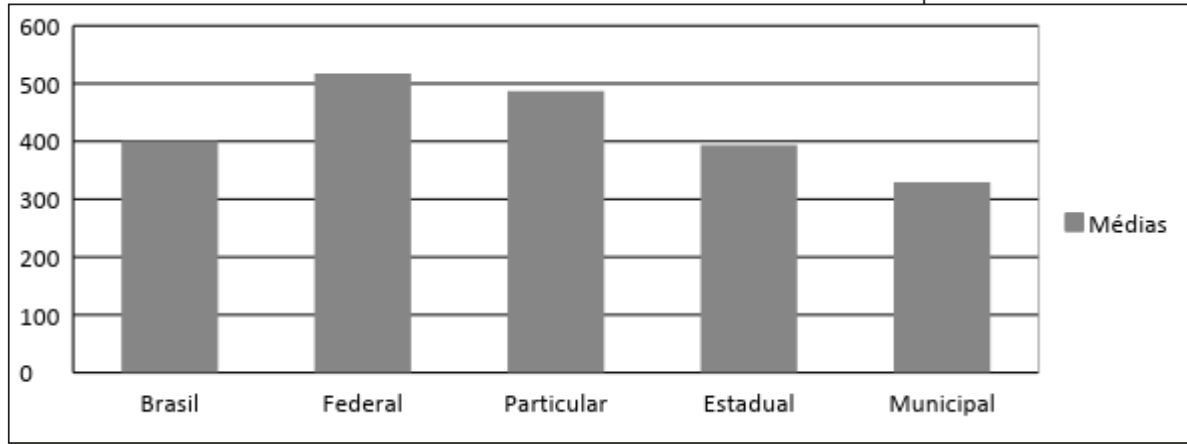

Fonte: elaboração com base em Brasil (2016a).

As análises do Gráfico 3 indicam que as escolas em nível federal apresentaram as melhores notas na prova, inclusive superior à média nacional. Por outro lado, devido à grande concentração de alunos fora da faixa adequada, ou seja, quinze anos, que ainda estão nas séries anteriores ao sétimo ano, estes se encontram nas escolas municipais, ou seja, com as menores notas no Pisa (BRASIL, 2016a).

Por conseguinte, os estudantes das escolas estaduais, que representam a maioria presente no Ensino Médio, apresentaram nota maior que a das escolas municipais. E, por fim, os dados do Gráfico 3 confirmam os estudos de Muri e Ortigão (2013), ao demonstrarem que as escolas particulares também obtiveram índice mais elevado que a nota nacional, uma vez que elas também possuem, em sua maioria, estudantes de quinze anos no Ensino Médio possuidores de condições socioeconômicas mais altas e melhor qualidade de ensino.

Ao levar em consideração a nota média dos estudantes e a unidade administrativa, não podemos deixar de analisar o perfil socioeconômico e cultural deles. Em relação a esse aspecto, os dados do Pisa 2006 demonstram que os estudantes de perfil socioeconômico baixo, ou seja, $38,3 \%$ dos participantes, estavam no nível 0 , na outra ponta, $0,6 \%$, representados por aqueles de maior alto nível socioeconômico, estavam no nível 4. Em contrapartida, 32,2\% estavam no nível 2 (MURI; ORTIGÃO, 2013).

Esses dados vão ao encontro do que se observa no Gráfico 3, ao se observar as notas mais baixas nas escolas públicas, municipais e estaduais, indicando que políticas públicas devem ser colocadas em práticas para que se tenha escolas públicas e de ensino com qualidade para todos os brasileiros, conforme já mencionado no trabalho de Medeiros, Jaloto e Santos (2017).

Em relação à nota do Brasil, no Pisa é necessário afirmar que, apesar desse indicador ter como finalidade analisar as melhorias da aprendizagem no país, no caso brasileiro, 
as notas refletem um quadro de distorções da real situação da educação brasileira. De acordo com Araújo e Tenório (2017), o Inep, juntamente a OCDE promoveu um nivelamento dos estudantes brasileiros participantes da prova de 2015, com um limite de idade mínima, de seis anos de escolarização, ou seja, cursando o sétimo ano do Ensino Fundamental, o que exclui aqueles alunos que não tinham esse limite mínimo de escolarização, para a realização da prova.

Quando se analisam as notas médias do Pisa, nas diferentes unidades administrativas deve-se levar em consideração também a jornada média diária, de aulas, que os alunos são impostos nas escolas. Essa média de horas/diárias é maior nas escolas particulares e nas escolas públicas federais e, menor, consequentemente, nas escolas estaduais e municipais, influenciando a qualidade de ensino ofertada nos diferentes tipos de unidades escolares, o que justificaria também as menores notas nessas duas últimas unidades escolares (WAISELFISZ, 2009).

É possível ainda observar as notas de cada estado brasileiro. Dessa forma, no Gráfico 4, apresentamos as médias dos estudantes em Ciências, no Pisa em 2015.

Gráfico 4 - Médias dos alunos em ciências, no Pisa 2015, por Estado brasileiro

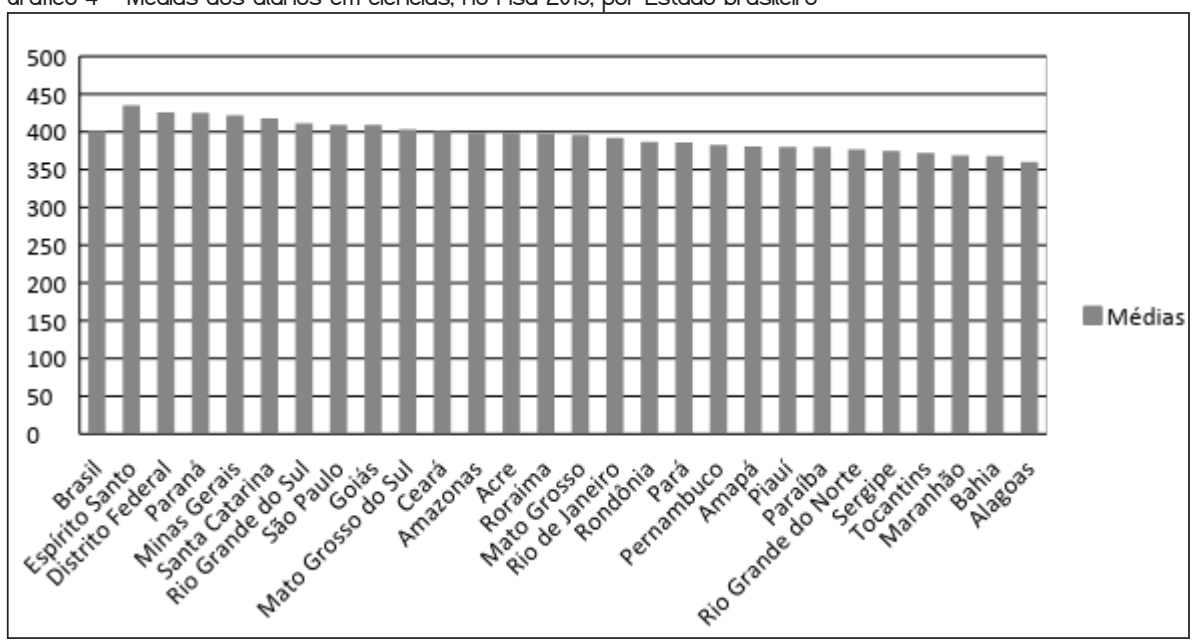

Fonte: elaboração com base em Brasil (2016a).

As análises do Gráfico 4 apontam que o Estado com a maior nota no conteúdo de Ciências, da prova Pisa de 2015 foi o do Espírito Santo, enquanto que o Estado do Alagoas obteve a menor nota, em comparação com os outros estados brasileiros e a nota nacional. 
Uma forma de analisarmos os dados do Gráfico 4 é compararmos as notas do Espírito Santo com a de Alagoas, levando-se em consideração a porcentagem de alunos, nos respectivos anos escolares, como descrito no Tabela 3.

Tabela 3 - Estudantes por Unidade de Federação

\begin{tabular}{lrrrrrrr}
\hline & \multicolumn{7}{c}{ Ano Escolar } \\
\cline { 2 - 8 } & \multicolumn{1}{c}{ UF } & \multicolumn{1}{c}{9} & \multicolumn{1}{c}{10} & 11 & \multicolumn{1}{c}{12} \\
\hline Brasil & $3,5 \%$ & $6,4 \%$ & $12,5 \%$ & $35,9 \%$ & $39,2 \%$ & $2,5 \%$ \\
AL & $11,2 \%$ & $13,7 \%$ & $17,0 \%$ & $27,0 \%$ & $25,3 \%$ & $5,9 \%$ \\
ES & $4,1 \%$ & $6,4 \%$ & $11,6 \%$ & $43,3 \%$ & $33,5 \%$ & $1,1 \%$ \\
\hline
\end{tabular}

Fonte: elaboração com base em Brasil (2016a).

Ao analisarmos a porcentagem de estudantes com 7, 8 e 9 anos, nos dois Estados brasileiros, veremos que em Alagoas, somam 41,9\%, enquanto que no Espírito Santo, essa somatória é de $22,1 \%$, uma diferença de $19,8 \%$. Essa diferença vai refletir diretamente nas notas desses dois estados, uma vez que, em Alagoas 41,9\% dos estudantes que fizeram a prova estavam no Ensino Fundamental ainda, enquanto que no Espírito Santo essa porcentagem cai para 22,१\%. Em outras palavras, o número de estudantes no Ensino Médio no Espírito Santo que fizeram a prova Pisa é maior que o número de estudantes de Alagoas.

Os dados obtidos no Inep puderam identificar a amostra de estudantes que participaram do Pisa 2015, composta de estudantes "[...] do sexo feminino (51,5\%), matriculados no Ensino Médio (77,7\%) de uma rede de ensino estadual $(73,8 \%)$ localizada em área urbana $(95,4 \%)$ e no interior (76,7\%)" (BRASIL, 2015, p. 34).

Ao término dessas análises concordamos com Araújo e Tenório (2017), ao afirmarem que, durante as buscas por dados para a realização deste trabalho não foram encontrados, de forma clara, relação direta entre os resultados do Pisa e ações, no sentido de criação de políticas públicas para a melhoria da educação brasileira.

Em especial, no caso de Ciências, encontramos ausências de políticas para a melhoria desse ensino, desestímulo aos profissionais dessa área, sendo delegados em segundo plano, posto que a maioria das políticas públicas são para as áreas de Português e Matemática, como já demonstrado nos estudos de Garcia et al., (2018). Ainda nessa área de Ciência foi possivel notar uma pequena amostra de trabalhos específicos dessa área e desses, poucos que se destinam, com profundidade a analisar ações realizadas para a criação de políticas educacionais de melhorias para o ensino de ciências. 


\section{CONSIDERAÇÕES FINAIS}

0 presente artigo teve como propósito buscar e analisar os dados do Pisa, referentes aos conteúdos de Ciências, no ano de 2006 e os de 2015. Ao se fazer essas análises, pode-se notar uma estagnação nos resultados brasileiros, nas edições onde o Brasil teve participação.

Ao comparar as notas brasileiras entre os anos citados, nota-se uma pequena alteração nesse índice, o que não representa de fato melhorias na educação devido às distorções realizadas, entre elas a idade/ano escolar mínimo para a realização da prova. Quando se fala em qualidade da educação, em relação aos conteúdos de Ciências, campo específico de análise nesse artigo, devemos levar em consideração a capacidade que os estudantes do Ensino Básico devem possuir para compreender Ciência, e, utilizá-la, relacionando-a com a tecnologia e saber aplicar esses conhecimentos na prática, no meio social em que se vive. Em relação a essas características, da alfabetização científica, cobrada na prova, os estudantes brasileiros não estão bem, posto que a grande porcentagem dos participantes não consegue superar o nível 2, mínimo de exigência para que esse estudante possa ser alfabetizado cientificamente.

Em contrapartida, os dados obtidos nas mais variadas fontes descritas anteriormente apontam que o Brasil ainda tem um grande desafio pela frente, o índice de evasão/abandono dos alunos no Ensino Fundamental e principalmente Ensino Médio, o que traz consequências negativas para o desenvolvimento social, tecnológico e educacional brasileiro.

Após as análises realizadas, em relação ao conteúdo de ciências, no Pisa, concordamos com Araújo e Tenório (2017), ao afirmarem que políticas públicas voltadas para a ação, no sentido de melhorias da qualidade da educação devem ser colocadas em prática. Uma vez que não foram encontrados trabalhos que relacionam o Pisa com melhorias educacionais.

Concordamos com Boldarine, Barbosa, Annibal (2017) ao afirmarem que as avaliações externas devem ser analisadas e levadas em consideração para as melhorias da aprendizagem no Ensino Básico e não somente como ponto de rankeamento de escolas, controle por parte dos governos ou formas de apontar culpados para os pontos fracos do ensino.

As políticas de avaliação dos sistemas escolares trazem mudanças curriculares e pedagógicas, com consequências para a aprendizagem dos estudantes. Por outro lado, elas não estão promovendo melhorias qualitativas na Educação Básica no sentido de diminuir as desigualdades sociais existentes. Assim, novas práticas devem ser colocadas nas escolas, principalmente na atual situação brasileira, de mudanças da Base Nacional Comum Curricular (BNCC) e, como consequência, dos currículos do Ensino Básico e do ensino de Ciências. 


\section{REFERÊNCIAS}

ARAÚJO, M. de L. H. S.; TENÓRIO, R. M. Resultados brasileiros no Pisa e seus (des)usos. Estudos em Avaliação Educacional. São Paulo, v. 28, n. 68, p. 344-380, maio/ago. 2017.

BARRETO, F. C. de S.; DOMINGUES, I. 0 PNPG 2011-2020: os desafios do país e o sistema nacional de pós-graduação. Educação em Revista. Belo Horizonte, 2012, v. 28, n. 3, p.17-53.

BOLDARINE, R. F.; BARBOSA, R. L. L.; ANNIBAL, S. F. Tendências da produção de conhecimento em avaliação das aprendizagens no Brasil (2010-2014). Estudos em Avaliação Educacional. Fundação Carlos Chagas, São Paulo, v. 28, n. 67, p. 160-189, jan./abr. 2017. Disponível em: http://publicacoes.fcc.org.br/ ojs/index.php/eae/article/viewFile/4244/3346 Acesso em: 03 maio 2017.

BONAMINO, A.; COSCARELLI, C.; FRANCO, C. Avaliação e letramento: concepções de aluno letrado subjacentes ao Saeb e ao PISA. Educação e Sociedade. Campinas, v. 23, n. 81, p. 91-113, dez. 2002. Disponível em: http://www.cedes.unicamp.br. Acesso em: 15 abr. 2017.

BRASIL. Brasil no PISA 2015: análises e reflexões sobre o desempenho dos estudantes brasileiros / OCDE-Organização para a Cooperação e Desenvolvimento Econômico. São Paulo: Fundação Santillana, 2016a.

BRASIL. Diretoria de Avaliação da Educação Básica. Brasil no PISA 2015: sumário executivo. Brasília, 2015. Disponivel em: http://download. inep.gov.br/acoes_internacionais/Pisa/documentos/2016/ Pisa_brasil_2015_sumário_executivo.pdf. Acesso em: 26 jun. 2018.

BRASIL. Instituto Nacional de Estudos e Pesquisas Educacionais Anísio Teixeira (INEP). Pisa 2015: Análises e Reflexões Sobre o Desempenho dos Estudantes Brasileiros. São Paulo: Fundação Santillana, 2016b.

BRASIL. Lei n. 9394, de 20 de dezembro de 1996. Lei de Diretrizes e Bases da Educação Nacional. Diário Oficial da União. Braślia, DF, 20 dez. 1996.

CALDERÓN, A. l.; BORGES, R. M. Avaliação Educacional: Uma abordagem à luz das revistas cientificas brasileiras. Revista lbero-americana de Evaluación Educativa, v. 6, p. 167-183, 2013.

CARVALHO, L. M. Pisa, Política e Conhecimento em Educação. Educação e Sociedade. Campinas, v. 37, n. 136, p. 601-607, jul.-set., 2016. Disponivel em: http://www.scielo.br/pdf/es/v37n136/1678-4626es-37-136-00601.pdf. Acesso em: 06 abr. 2017.

CASTRO, M. H. G. Sistemas de avaliação da educação no Brasil: avanços e novos desafios. São Paulo em Perspectiva, São Paulo, Fundação Seade, v. 23, n. 1, p. 5-18, jan./jun. 2009. Disponível em: http:// www.seade.gov.br>; <www.scielo.br. Acesso em: 06 abr. 2017. 
CORREIA, J. A. de A. V.; ARELARO, L. R. G.; FREITAS, L. C. Para onde caminham as atuais avaliações educacionais? Educação e Pesquisa. São Paulo, v. 41, n. especial, p. 1275-1281, dez., 2015. Disponível em: http://dx.doi.org/10.1590/S1517-9702201508148846. Acesso em: 14 abr. 2017.

DIAS SOBRINHO, J. Avaliação: Políticas Educacionais e Reformas da Educação Superior. São Paulo: Cortez, 2003.

FREITAS, L. C. et al. Avaliação e políticas públicas educacionais: ensaios contra regulatórios em debate. Campinas: Leitura Crítica, 2012.

GARCIA, P. S. et al. Austrália, Brasil e Canadá: Impacto das Avaliações no Ensino de Ciências. Estudos em Avaliação Educacional. São Paulo, v. 29, n. 70, p. 188-221, jan./abr. 2018.

LIBÂNEO, J. C.; OLIVEIRA, J. F.; TOSCH, M. S. (org.) Educação Escolar: políticas, estrutura e organização. São Paulo: Cortez, 2012.

MAIA, P. F.; JUSTI, R. Desenvolvimento de habilidades no ensino de Ciências e o processo de avaliação: análise da coerência. Ciência \& Educação, Bauru, v. 14, n. 3, p. 431-450, 2008.

MAINARDES, J. As relações entre currículo, pedagogia e avaliação no contexto das avaliações de sistemas educacionais. In: BAUER, A.; GATTI, B. A.; TAVARES, M. R. (Org.). Vinte e cinco anos de avaliação de sistemas educacionais no Brasil: implicações nas redes de ensino, no currículo e na formação de professores. v. 2. Florianópolis: Insular, 2013.

MEDEIROS, L.; JALOTO A.; e SANTOS, A. V. F. A área de Ciências nas avaliações internacionais de larga escala. Estudos em Avaliação Educacional. v. 28, n. 68, p. 512-537, maio/ago. 2017.

MURI, A. F.; SOARES, T. M.; e BONAMINO, A. Funcionamento diferencial dos itens de Ciências do PISA: Brasil e Japão. Estudos em Avaliação Educacional. São Paulo, v. 28, n. 68, p. 538-570, maio/ago. 2017.

MURI, A. F., ORTIGÃO, M. I. R. A Alfabetização Científica Brasileira: um estudo a partir dos dados do PISA 2006. ANAIS da VII Reunião da ABAVE. Avaliação e currículo: um diálogo necessário. n. 7, 2013 p. 385400.

ORGANIZAÇÃO PARA A COOPERAÇÃO E DESENVOLVIMENTO ECONÔMICO. PISA 2006 Technical Report. Paris: Organization for Economic Co-Operation and Development, 2007.

PIZARRO, M. V.; JÚNIOR, J. L. Os sistemas de avaliação em larga escala e seus resultados: o PISA e suas possiveis implicações para o ensino de ciências. Revista Ensaio, Belo Horizonte, v. 19, n. 2776, p. 1-24, 2017.

SASSERON, L. H.; CARVALHO, A. M. P. de. Alfabetização Científica: Uma Revisão Bibliográfica. Investigações em Ensino de Ciências, v.16, n. 1, p. 59-77, 2011. 
SOARES, S. S. D.; NASCIMENTO, P. A. M. Evolução do desempenho cognitivo dos jovens brasileiros no PISA. Cadernos de Pesquisa. São Paulo: Fundação Carlos Chagas; Campinas: Autores Associados, v. 42, n. 145, p. 68-87, jan./abr. 2012. Disponivel em: http://www.scielo.br/scielo.php?script=sci_ arttext\&pid=S0100-15742012000100006\&lng=pt Acesso em: 18 maio 2017.

TEIXEIRA, J. N. Categorização do nível de letramento científico dos alunos de Ensino Médio. Dissertação (Mestrado em Ciências) - Universidade de São Paulo. São Paulo, 2007.

VIEIRA, A. M. Acordes e dissonâncias do letramento científico proposto pelo PISA 2015. Estudos em Avaliação Educacional. São Paulo, v. 28, n. 68, p. 478-510, maio/ago. 2017.

WAISELFISZ, J. J. 0 ensino das Ciências no Brasil e o PISA. São Paulo: Sangari, 2009.

Endereço para correspondência: Rua Professor Dr. Euryclides de Jesus Zerbini, 1.516, Parque Rural Fazenda Santa Cândida, 13.087-571, Campinas, São Paulo, Brasil; samuelm@puc-campinas. edu.br 
